\title{
EN EL CÓMIC NADIE PUEDE OÍR TUS GRITOS: A PROPÓSITO DE LAS ADAPTACIONES DEL CINE AL CÓMIC ${ }^{1}$
}

Eduard BAILE LÓPEZ

Dept. de Filologia Catalana-Aula de Còmic (Universitat d'Alacant)

\section{RESUMEN}

En este artículo se propone un acercamiento a las adaptaciones del cine al cómic, a menudo dejadas de lado en comparación con el fenómeno inverso, más habitual y de mayor impacto mediático. Ciertamente, el camino que lleva del celuloide a las viñetas suele estar plagado de obras olvidables, a menudo fruto tan solo de intereses publicitarios, pero pensamos que, bajo una premisa intermedial, se puede proponer un compendio breve de ejemplos merecedores de análisis. Así pues, queremos presentar una propuesta de diez ítems que se constituyen como una suerte de canon artístico expuesto al debate. Posteriormente, una de las obras escogidas, Alien: The Illustrated Story (1979), será objeto específico de reflexión como ítem modélico.

Palabras clave: cómic, cine, adaptación, intermedialidad.

\section{LOS CAMINOS OUE CONDUCEN A LAS ADAPTACIONES (EN CÓMIC) SON INESCRUTABLES}

La valoración y la conveniencia de adaptar una obra de un medio a otro ha sido, a menudo, un tema controvertido, bien por juicios apriorísticos de muy dudosa profundidad respecto a las cualidades supuestamente inherentes a cada arte (abandonemos ya el debate sobre la alta y la baja cultura) o bien, en un plano de crítica intelectual más honesta, por las dificultades de traslación si fuera la circunstancia de que uno de los ítems estuviera

1 La elaboración de este artículo se integra dentro del proyecto europeo Investigation on Comics and Graphic Novels in the Iberian Cultural Area (CA19119-iCOn-MICS) y de la red de docencia universitaria Coneixement del cànon artístic del còmic a les aules universitàries: possibilitats didàctiques. Anàlisi comparada de diverses universitats (REDI3CE4698), perteneciente al programa I3CE d'Investigació en Docència Universitària del curso 2019-2020 en la Universitat d'Alacant. 
íntimamente ligado a las peculiaridades del lenguaje de su medio primitivo. En todo caso, es un hecho incontrovertible que las adaptaciones son susceptibles de ser analizadas con rigor para, así, comprobar si responden únicamente a la táctica comercial del merchandising (esto es, entender que una adaptación sirve para promocionar la obra original en la misma medida en que lo hace una camiseta o una taza) o si, por el contrario, funcionan como artefactos culturales autónomos, bien porque superan sus orígenes espurios o porque ya parten desde el principio de una voluntad autoral insoslayable.

En este sentido, cabe decir que el propósito de este artículo remite, precisamente, a esta última vía, la de llamar la atención sobre adaptaciones que cuentan con la suficiente enjundia para ser consideradas como algo más que receptáculos vacíos de significado real al margen del ítem primigenio en el que se basan². Más concretamente, queremos focalizar en versiones de filmes vertidos al cómic, un proceder que se suele caracterizar en mayor medida por la creación de artefactos inanes ${ }^{3}$ que solo adquieren sentido como parte de la estrategia de provocar en el consumidor la necesidad de comprar cualquier producto relacionado con el objeto primario, que por haber dado lugar a, si no obras maestras, al menos a unos cuantos ejemplos dignos. Sin embargo, lo cierto es que, absorbidos por la costumbre ya casi consuetudinaria ${ }^{4}$ de trasladar sagas historietísticas ${ }^{5}$ a las salas cinematográficas y a las plataformas digitales, puede que hayamos descuidado la atención por el fenómeno inverso y, así, puede que también hayamos dejado de valorar algunas versiones en la medida en que lo merecen.

Así pues, en las líneas subsiguientes defenderemos que en la traslación del medio fílmico al campo de las viñetas es posible focalizar sobre ítems de calidad contrastada y que disponen, por sí mismos, de alicientes que los configuran como lecturas primordiales. Por esto, bajo una premisa sencilla de criterios analíticos vinculados con el concepto del canon artístico, haremos memoria breve (una propuesta de selección cualitativa, por así decir) de una decena de ejemplos interesantes para, posteriormente, priorizar una obra concreta (Alien: The Illustrated Story, pergeñada en 1979 por Archie Goodwin y Walter Simonson) que consideramos modélica, sin que ello obste para reconocer que en futuras pesquisas (¿tal vez en una monografía?) quizá quepa proponer una panorámica de mayor espectro y que ponga luz y taquígrafos sobre un mayor número de artefactos.

Asimismo, pensamos que el hecho de plantear un análisis de obras vertidas de un medio a otro abre las puertas a comentarios sugerentes sobre conceptos diversos característicos o, al menos, fronterizos, con la perspectiva intermedial. Sin ánimo, por descontado, de entrar en disquisiciones teóricas complejas que merecerían ser objeto central en otro tipo de artículo, ciertamente la confrontación entre el medio cinematográfico y el historietístico nos facultará para verter ocasionalmente gotas vinculadas con la narrativa transmedia (Jenkins,

2 Aunque, por supuesto, este segundo factor también podría ser igualmente digno de reflexión, solo que por otros motivos: a nuestro juicio, la crítica académica, lo es no por el objeto de estudio sino por el enfoque riguroso del análisis.

3 No exentos de disfrute: ¡Llévese la película a casa! era la frase (o una similar) que, frecuentemente, rezaba en portada del tebeo.

4 Quizá también por un complejo de inferioridad derivado de aquella deleznable letanía del cómic como el cine para los pobres.

5 Manga y anime al margen, eminentemente las franquicias superheroicas y, en menor medida, las de la bande dessinée, es decir, los personajes por encima de las historias (Dixon y Graham, 2017). 


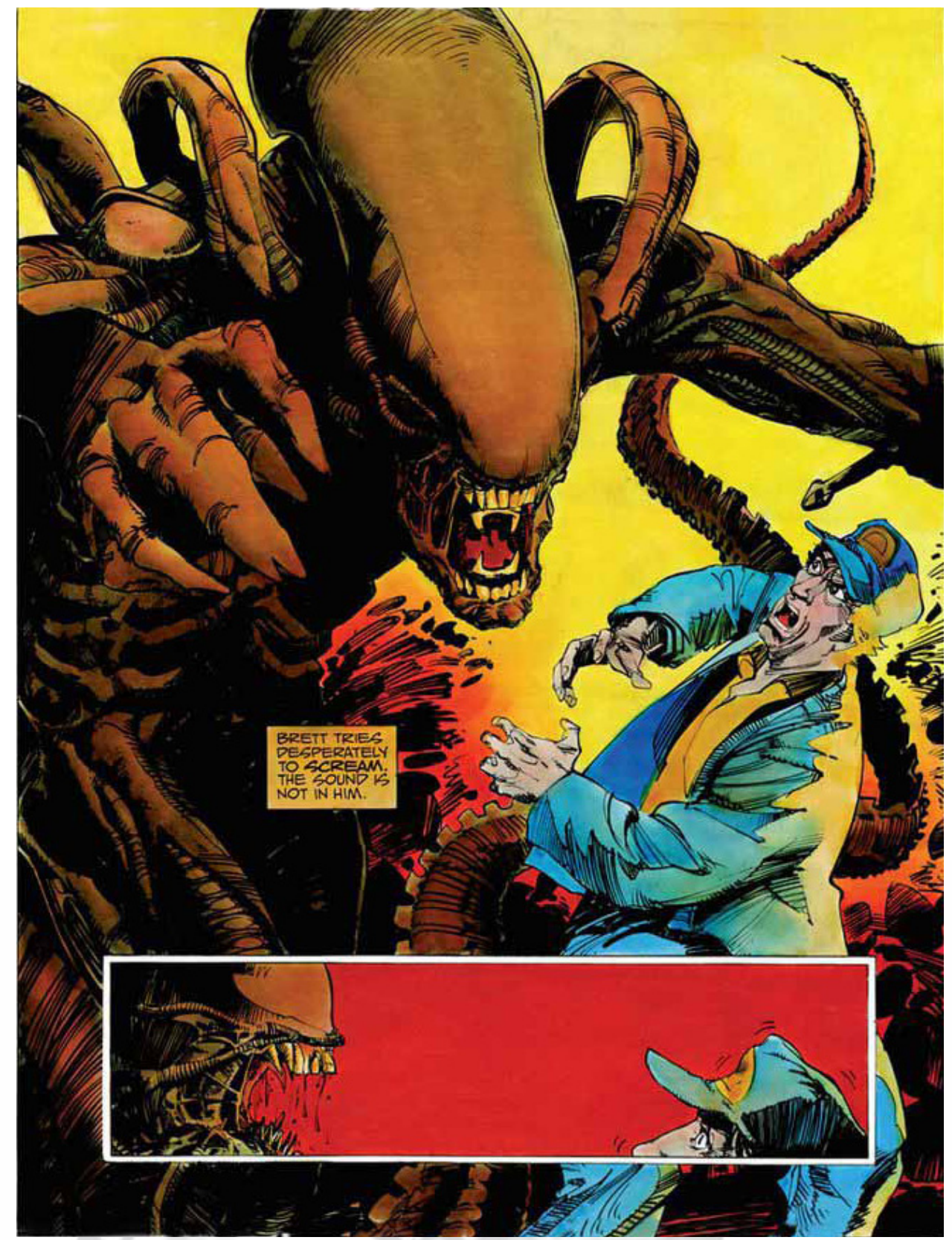

La criatura de pesadilla diseñada por H. R. Giger para enturbiar los sueños de los tripulantes de la nave Nostromo

2003; Scolari, 2013) ${ }^{6}$. Esto, a su vez, constituye la argamasa del concepto de la lectura multimodal (extensión del modelo de Kress y van Leeuwen, 2001, elaborada originalmente sobre la comunicación oral), es decir, la asunción de que el modo de aproximación a una manifestación cultural debe ser entendida según un prisma de interpretación acumulativa7.

6 En cierta manera, lo transmedia remite también a la intertextualidad (Kristeva, 1978; Genette, 1989), solo que pone el foco sobre la realidad mutante de las vías desde las que el lector/espectador/oyente accede a cualesquiera artefactos culturales.

7 Una iteración no substituye a la otra sino que ambas representan piezas diferentes del rompecabezas: dónde colocarlas y cómo descifrarlas ya dependerá de los intereses de la investigación o, en caso de enfoque didáctico, de la finalidad de la implementación. 
Finalmente, señalemos que el panorama resultante de que sea el cómic el medio meta de las adaptaciones seleccionadas, un ámbito en el que, por contraste (al menos, prototípicamente), es el lector el que determina en última instancia el ritmo y en el que se puede jugar con el nivel de iconicidad de la representación visual (que, además, parte de una materialidad ex novo, como destaca Altarriba, 2008) ${ }^{8}$, permite concebir su lenguaje específico como herramienta óptima para construir un proceso de lectura complejo en cuyo desciframiento, al sustentarse eminentemente en la solidaridad icónica (Groensteen, 1999: 82), se genera un espacio abierto (Yus, 1997; Ahmed, 2016) a la intervención del lector (intentio lectoris), que asume una posición de hacedor final del sentido en tensión con la voluntad del autor (intentio autoris).

\section{2. ¿QUÉ ES ADAPTACIÓN?, DICES MIENTRAS CLAVAS EN LAS VIÑETAS TU PUPILA EN CUATRICOMÍA}

Como ya hemos aludido antes, el debate en torno a la definición de qué es exactamente una adaptación se ha vinculado a menudo con el campo de la intertextualidad, puesto que en él se pone de manifiesto que las creaciones culturales no responden a motivaciones aisladas sino a interrelaciones constantes: cada obra previa actúa, en cierta manera, de abono enriquecedor de los artefactos venideros. En otros términos: nada es atemporal, ni crece en un vacío o en una torre de marfil inaccesible. Antes al contrario, cada ítem artístico está fuertemente determinado por su lugar en el tiempo, y eso incluye tanto lo que le es coetáneo como lo que le precede. Ocupa, en definitiva, un lugar en un telar que no cesa nunca de ser tejido.

No obstante, este artículo dista mucho de pretender llegar a un esclarecimiento semántico 9 de la adaptación de manera que, para fortalecer la apuesta por analizar aquellas versiones historietísticas que consiguen un grado de autonomía suficiente, optamos tan solo por remitir a la consideración de la adaptación como práctica transposicional (Sanders, 2005: 22), es decir, como acto de revisión. Así, pues, entendemos que, en buena medida, el trayecto hacia el éxito artístico se vincula con la intencionalidad autoral de asumir como propio el objeto original (hubiera o no en inicio un encargo empresarial) y, una vez completada esta especie de suplantación identitaria, establecer un diálogo de igual a igual. Si a este planteamiento añadimos, por mor del objeto central de este artículo, la intermedialidad (de ahí que hayamos también apuntado al fenómeno transmedia), se agudiza la idea de la apropiación ${ }^{10}$, más si cabe al tener en cuenta que el cómic, como arte de tensiones (Hatfield, 2009), aporta una gramática con un marcado carácter propio.

8 Bajo dicho parapeto, el de la pureza prometeica del fuego creador de los historietistas, se pueden cobijar perspectivas críticas que recurran a premisas tan sugerentes como la del Punctum de Barthes (1990) o la iconicidad como ilusión de realidad (Greimas y Courtés, 1982: 176-178; Zunzunegui, 2010: 55-97).

9 Por bien que se trata de referencias bibliográficas centradas en las relaciones con la literatura, es recomendable atender a Yexus (1996) y a Berone (2008) como visiones sugerentes sobre la adaptación como problema, en alusión a las dificultades derivadas de cambiar de medio y, por consiguiente, de lenguaje.

10 En puridad, Sanders (2005: 35) diferencia entre adaptación y apropiación en tanto que en este segundo caso la relación con el objeto original desemboca en la interpolación y en la crítica por oposición al planteamiento dialógico de aquel. Nosotros, sin embargo, consideramos que no son necesariamente conceptos estancos y que, en consecuencia, una buena adaptación no está exenta de un alto grado de apropiación, por más que haya obras que, efectivamente, se han empapado tanto de singularidad que las huellas del diálogo ya son casi imperceptibles (como botón de muestra, señalemos el caso notable de Apocalypse Now de Francis Ford Coppola respecto a Heart of Darkness de Joseph Conrad). 

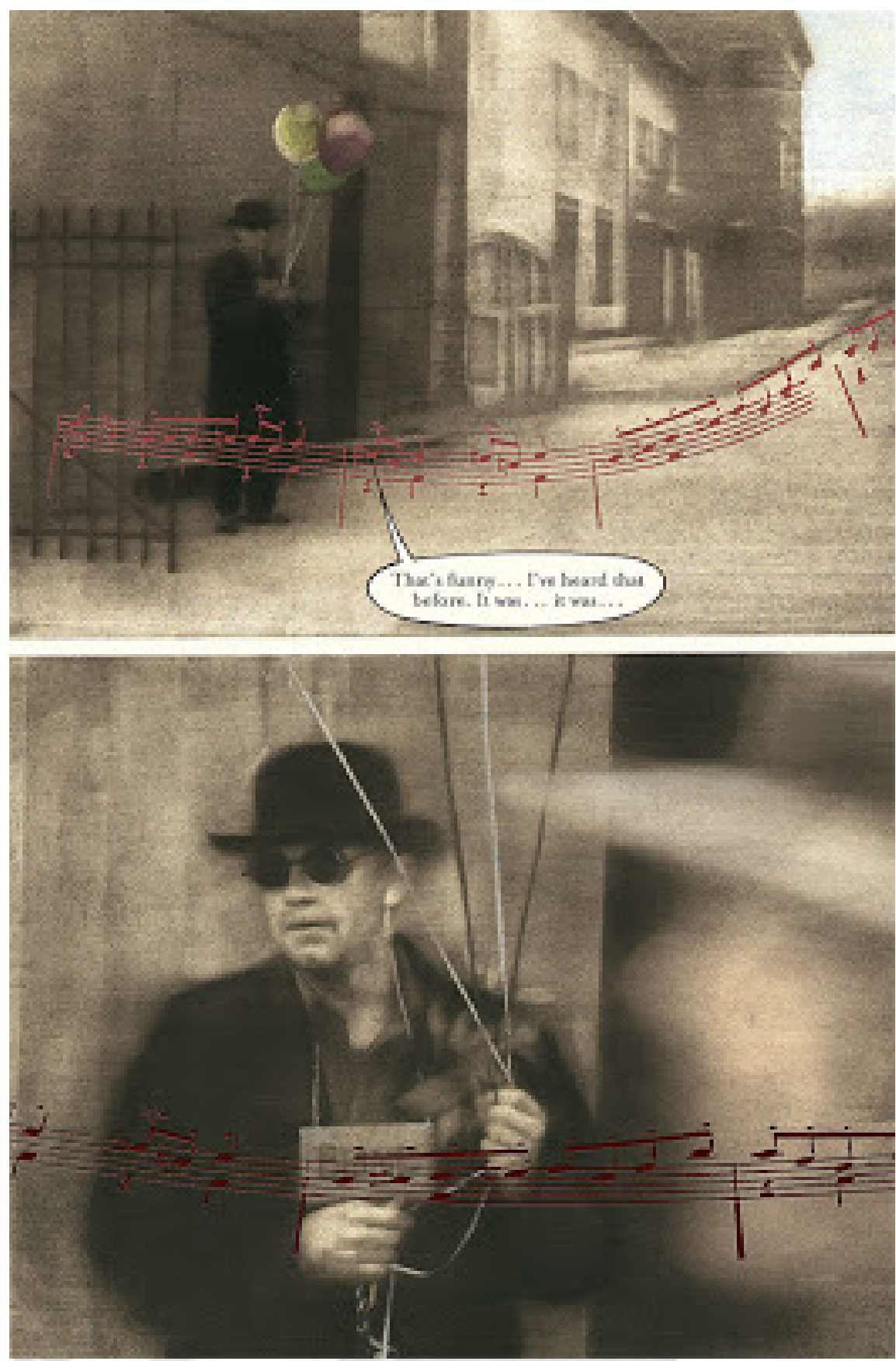

Contrastes intermediales: plasmación de la melodía de Peer Gynt en M (1990-1992) de Jon J Muth

En esta línea, ahondando en ideas ya aludidas en la introducción, valoramos que los elementos característicos del lenguaje del cómic frente al cine ${ }^{11}$, que confluyen en el sincretismo conceptual de la solidaridad icónica (ien el montaje, por lo que atañe al cine?), esto es, un proceso de lectura que remite más a lo sensorial intuitivo que a lo lineal

11 La manera de plasmar la sincronía y la diacronía en relación al espacio y al tiempo; el nivel de iconicidad del trazo; la materialidad ex novo de los signos; las metáforas visuales y las onomatopeyas, etc. (Matly, 2018, bajo una visión que remite más a la funcionalidad que a la semántica) frente al ángulo y movimiento de la cámara; el sonido; la iluminación; la realidad material que es capturada en pantalla, incluyendo aquí a los actores, etc. (Hill y Gibson, 1998; Cassetti, 2002). 
narrativo ${ }^{12}$, nos facultan para defender una idea de las adaptaciones al cómic como un modelo referencial de apropiación multimodal vía la interdisciplinariedad inherente a la integración prototípica de imagen y texto ${ }^{13}$.

Sin duda, como señala Sousanis (2015: 54), el medio en el que se piensa (se crea) afecta a nuestro modo de aprehender el conocimiento. De acuerdo a este presupuesto y parafraseando a Barthes (1973), estimamos que la piedra Rosetta del cómic como experiencia lectora reside en que el control del ritmo por parte del lector es, por contraste con el cine ${ }^{14}$, el factor determinante para crear un contexto favorecedor de la conversión de la adaptación en objeto de significado, dado que el objeto por sí mismo no está concluso sino abierto a negociación con respecto al planteamiento del historietista.

\section{HACIA UN CANON DE ADAPTACIONES (DEL CINE AL CÓMIC) PARA GOBERNARLOS A TODOS}

Dista mucho de la intención de este artículo plantear en sentido estricto una propuesta de canon artístico de adaptaciones del cine al cómic, esto es, de una selección de ítems bajo una premisa de exigencia cualitativa para determinar qué obras son aquellas que merece la pena preservar como lecturas referenciales. No obstante, dejando de lado que, entre otras consideraciones, es conveniente llegar al consenso mediante el cruce de visiones diversas para no caer en selecciones lastradas por el gusto personal, sí que queremos aprovechar este púlpito para destacar algunas obras que, indudablemente, representan un foco de interés en tanto que cómics meritorios como tales y no solo por su remisión al original. En el futuro, si contamos con la oportunidad, tal vez podamos tomar este breve listado para, junto con otros investigadores, construir una selección de mayor complejidad.

En todo caso, apuntemos que, para poder acometer esta sucinta selección (y, asimismo, ofrecer un marco para el análisis de una obra en concreto en el apartado 4 de este artículo), hemos tomado como punto de partida unos criterios desarrollados por el grupo Unicómic de la Universitat d'Alacant, al que pertenecemos en la faceta de coordinación académica (Rovira-Collado, 2017: 12-14) ${ }^{15}$ :

12 Obviamente, cuando confrontamos peculiaridades de lenguaje remitimos a lo más frecuente, en el caso del cine a la deuda adquirida con la narrativa decimonónica por parte de D. W. Griffith en adelante (Gimferrer, 2005: 19). No obstante, admitimos un rendija de crítica contra nuestra visión por la cual se deslizarían otras maneras de entender el montaje fílmico: tomando prestado el título de una película de José Luis Guerín, el lenguaje de un medio siempre está en construcción. En todo caso, permítanos el lector de este artículo la licencia de establecer un paradigma metodológico adecuado a nuestro objeto de estudio y dejemos para textos futuros la depuración del mismo.

13 O en su ausencia: así, por ejemplo, el caso de los cómics mudos, que no disponen de texto alfabético pero sí de guion puesto que en la historieta el dibujo ya asume esa condición.

14 Como ya hemos advertido en la nota 12, por necesidades metodológicas derivadas de la acotación que supone un artículo en contraste con una monografía, en la que se pueden matizar mejor las aseveraciones, aquí resaltamos las características convencionales de los lenguajes respectivos.

15 En origen, estos criterios parten de premisas vinculadas al mundo de la literatura infantil y juvenil, dado que a medio-largo plazo el grupo Unicómic, conformado por docentes de la Universitat d'Alacant en la Facultad de Educación, pretende establecer un paradigma de canon escolar del cómic según niveles educativos. No obstante, esto no es óbice para que dicho catálogo de criterios no se pueda aplicar, debidamente modificado, a otros contextos. Así pues, para este trabajo hemos aplicado una visión semiótica deudora de monografías como Muro Munilla (2004), Varillas (2009), Jiménez Varea (2016) y Bordes (2017), todas ellas fondeantes en la consideración del cómic como medio específico y que se caracteriza por conformar sus valores narratológicos en función de la idea de arquitectura gráfica. 
Tabla 1. Criterios de valoración de las adaptaciones del cine al cómic

\begin{tabular}{|c|c|}
\hline EJE DE VALORACIÓN CRÍTICA & DESCRIPCIÓN \\
\hline Autoría & $\begin{array}{l}\text { - Creadores participantes. } \\
\text { - Función de cada uno. } \\
\text { - Trayectoria profesional y características autorales. } \\
\text { - Sinergias del equipo creativo. }\end{array}$ \\
\hline Continente & $\begin{array}{l}\text { - Formato: álbum, comic book (grapa), integral, webcómic... } \\
\text { - Cubierta, portada, contraportada y guardas. }\end{array}$ \\
\hline Elementos narratológicos & $\begin{array}{l}\text { - Argumento. } \\
\text { - Tema principal y/o secundarios. } \\
\text { - Ideología. } \\
\text { - Construcción del significado. } \\
\text { - Elementos diegéticos del relato: personajes, espacio, tiempo, } \\
\text { acción... } \\
\text { - Elementos extradiegéticos del relato: punto de vista, focaliza- } \\
\text { ción, ocularización, niveles narrativos, voz narrativa... } \\
\text { - Géneros formales: biografía, memorias... } \\
\text { - Géneros temáticos: terror, western... }\end{array}$ \\
\hline Propuesta gráfica & $\begin{array}{l}\text { - Formato de página y viñetas. } \\
\text { - Estilo de dibujo. } \\
\text { - Componentes específicos: cartelas, bocadillos, líneas cinéticas... } \\
\text { - Encuadres. } \\
\text { - Paleta de colores. } \\
\text { - Rotulación. } \\
\text { - Metáforas visuales. } \\
\text { - Elipsis. } \\
\text { - Tipo de relación que se establece entre texto e imagen. } \\
\text { - Monosemia/polisemia interpretativa a partir de las explicaturas/ } \\
\text { - implicaturas visuales. } \\
\text { - Interdisciplinariedad. }\end{array}$ \\
\hline
\end{tabular}

A partir, pues, de este eje crítico, cabe abordar brevemente un recorrido por diez propuestas de adaptaciones del cine al cómic que, a nuestro juicio, serían candidatas plausibles a figurar en una selección artística ${ }^{16}$. Como ya hemos dejado entrever desde el resumen mismo, se trata tan solo de poner sobre la mesa un listado a manera de sugerencia sobre el que poder crecer. Queda, pues, para un texto más ambicioso el análisis detallado de cada obra, si bien aportamos algunas notas urgentes:

16 El lector atento percibirá que la selección remite a obras que, si bien pueden tener un origen serializado, en su forma completa se constituyen como ítems cerrados, accesibles en un único volumen para la posteridad (bien se podría argumentar que son artefactos que o remiten directamente a la etiqueta novela gráfica, según García, 2010, o la preconizan, en el caso de los más antiguos). En consecuencia, indiquemos que queda en el debe de este artículo otras opciones vinculadas al fenómeno de las franquicias y que, por consiguiente, podrían abrir las puertas a explorar el concepto de los universos expandidos, tal vez tomando como referencia iniciática el 2001: A Space Odyssey (1976) de Jack Kirby, al que siguió una serie regular de apenas unos pocos números. 
Tabla 2. Propuesta de canon artístico de adaptaciones del cine al cómic

\begin{tabular}{|c|c|}
\hline Obra seleccionada & Breve comentario sobre el motivo de selección \\
\hline $\begin{array}{l}\text { Alien: The Illustrated Story (1979) } \\
\text { de Archie Goodwin (guion) y Walter } \\
\text { Simonson (dibujo). } \\
\text { Basada en Alien (1979), dirigida por } \\
\text { Ridley Scott. }\end{array}$ & $\begin{array}{l}\text { Obra escogida para el análisis específico en el apartado } 4 \\
\text { del presente artículo. } \\
\text { Última edición en español: Diábolo Ediciones, Madrid, } \\
2012 \text {. }\end{array}$ \\
\hline $\begin{array}{l}\text { Outland (1981-1982) de Jim Steranko } \\
\text { (autor completo). } \\
\text { Basada en Outland (1981), dirigida por } \\
\text { Peter Hyams. } \\
\text { Conocida en España como Atmósfera } \\
\text { cero. }\end{array}$ & $\begin{array}{l}\text { Trabajo excepcional de diseño de página, en la que Ste- } \\
\text { ranko incrusta una disposición tal (doble splash page en la } \\
\text { parte superior combinada con secuencias de viñetas con- } \\
\text { secutivas en la parte inferior) que consigue aunar la sensa- } \\
\text { ción de movimiento de los fotogramas originales y la sin- } \\
\text { cronicidad de las diversas acciones. } \\
\text { Asimismo, cabe destacar un grado de iconicidad del di- } \\
\text { bujo que, sin abandonar un figurativismo vagamente rea- } \\
\text { lista, remite a lo geométrico y, así, ahonda en la sensación } \\
\text { de angustia reminiscente del filme, un remedo notable } \\
\text { en clave de ciencia ficción del western High Noon (1952), } \\
\text { traducida como Solo ante el peligro, vía el recurso a la } \\
\text { ambientación opresiva de la inmensidad del espacio. } \\
\text { Última edición en español: Eurocómic, Fuenlabrada, } \\
1982 \text { (descatalogado). }\end{array}$ \\
\hline $\begin{array}{l}\text { Creepshow (1982) de Stephen King } \\
\text { (guion) y Bernie Wrightson (dibujo). } \\
\text { Basada en Creepshow (1982), dirigida } \\
\text { por George A. Romero. }\end{array}$ & $\begin{array}{l}\text { Puesto que la película ya es, por sí misma, un homenaje a } \\
\text { las historias cortas de terror con twisted ending de la EC } \\
\text { Comics de los años cincuenta (con efectos evocadores del } \\
\text { tipo de impresión y de color, la enmarcación de la panta- } \\
\text { lla en viñetas, etc.), la adaptación retoma esa influencia y } \\
\text { puede ser considerada, en verdad, como una especie de } \\
\text { almanaque extra de aquellas cabeceras como Tales from } \\
\text { the Crypt y otras. } \\
\text { La morbosidad a medio camino entre el terror y el descrei- } \\
\text { miento paródico se apoya en el dibujo enfermizo pero, } \\
\text { a su vez, humorístico y un tanto caricaturesco, de Bernie } \\
\text { Wrightson, heredero de Graham 'Ghastly' Ingels, uno de } \\
\text { los estandartes de la series originales. Complementaria- } \\
\text { mente, añadamos que la portada está firmada por Jack } \\
\text { Kamen, artista de la EC. } \\
\text { Última edición en español: Planeta Cómic, Barcelona, } \\
2019 \text {. }\end{array}$ \\
\hline
\end{tabular}




\begin{tabular}{|l|}
\hline Obra seleccionada \\
\hline M (1990-1992) de Jon J Muth (autor \\
completo). \\
Basada en M - Eine Stadt sucht einen \\
Mörder (1931) de Fritz Lang.
\end{tabular}

Breve comentario sobre el motivo de selección

Aparentemente lastrada por el dibujo de base fotográfica de Muth, esta adaptación sobresale por la capacidad de evocar la crudeza mediante una atmósfera malsana e inquietante. En cierta manera, el estatismo (ocasionalmente retorcido por secuencias rápidas y emborronamientos de la imagen tal que una fotografía ajada) se revela como herramienta útil para rememorar el paroxismo de los ojos de Peter Lorre encarnando a un asesino en serie de niños.

La ausencia de sonido, algo no baladí en la adaptación de un filme que juega con la famosa melodía identificativa del Peer Gynt de Edvard Grieg como leitmotiv que anuncia al psicópata, se hace patente inevitablemente pero el autor consigue compensarlo mediante notas discordantes como el uso marginal de colores vivos incrustados en el sepia habitual y, también, el recurso de la tipografía característica de la anotación musical, que se dispersa por la página como si estuviera en movimiento.

Última edición en español: Rossell, Girona, 2009.

Bram Stoker's Dracula (1992) de Roy Thomas (guion) y Mike Mignola (dibujo).

Basada en Bram Stoker's Dracula (1992), dirigida por Francis Ford Coppola.
Si bien se puede alegar que Roy Thomas peca de verbosidad en algunos momentos (reminiscencias, seguramente, de su formación como guionista para Marvel de los sesenta en adelante, cuando abundaba el sentido prosístico en cartelas y bocadillos), no es menos cierto que demuestra una pericia de artesano consumado a la hora de modelar una narrativa clara (casi clarividente, incluso).

En todo caso, el rey de la función es Mignola, que aborda el grafismo con un sentido de la atmósfera que raya la excelencia en cuanto a lo ominoso y resulta, además, muy adecuado para evocar el romanticismo estilizado del mito vampírico.

Última edición en español: Norma, Barcelona, 2019.

Batman (1989) de Dennis O’Neil (guion) y Jerry Ordway (dibujo).

Basada en Batman (1989), dirigida por Tim Burton.
Ciertamente, de todas las obras seleccionadas, se trata de la más dependiente de sus orígenes como encargo empresarial para apoyar el estreno de la película en que se basa. Es por ello que, narrativamente, por bien que muestra un alto grado de artesanía merced al hábil Dennis O'Neil, no accede a un grado suficiente de autonomía. Sin embargo, el dibujo brillante de Jerry Ordway consigue que aquello que, precisamente, podría jugar más en su contra, esto es, la sensación de estar reproduciendo los fotogramas mecánicamente en viñetas, se convierta en un punto a favor: nunca la sensación de llevarse la película a casa en papel fue más cierta. Sin duda, es el ejemplo más depurado de orfebrería mainstream en torno a una adaptación.

En esta línea, la sobriedad en el despliegue de tropos gráficos, el control preciso de la focalización y el dominio excelente de la anatomía le otorgan una pátina de manual para la posteridad.

Última edición en español: ECC, Barcelona, 2020. 


\begin{tabular}{|c|c|}
\hline Obra seleccionada & Breve comentario sobre el motivo de selección \\
\hline $\begin{array}{l}\text { El gabinete del Dr. Caligari (2012) de } \\
\text { Diego Olmos (autor completo). } \\
\text { Basada en Das Cabinet des Dr. Caligari } \\
\text { (1920), dirigida por Robert Wiene. }\end{array}$ & $\begin{array}{l}\text { La locura geométrica del expresionismo alemán es fago- } \\
\text { citada por Diego Olmos en un dibujo marcadamente ex- } \\
\text { presivo que no huye sino que, todo lo contrario, abraza el } \\
\text { carácter teatral del original para, así, desembocar en esa } \\
\text { misma sensación de incerteza ante el espejismo y lo real. } \\
\text { Asimismo, mediante la exageración facial confluye con el } \\
\text { filme en el logro de evocar expresividad en compensación } \\
\text { por la falta de sonido. } \\
\text { Última edición en español: EDT, Barcelona, } 2012 \text { (desca- } \\
\text { talogado). }\end{array}$ \\
\hline $\begin{array}{l}\text { Der Himmel über Berlin (2015) de } \\
\text { Sebastiano Toma y Lorenzo Toma } \\
\text { (obra a cuatro manos). } \\
\text { Basada en Der Himmel über Berlin } \\
\text { (1987), dirigida por Wim Wenders. } \\
\text { Conocida en España como El cielo } \\
\text { sobre Berlín. }\end{array}$ & $\begin{array}{l}\text { De procedencia teatral, los autores, padre e hijo, presen- } \\
\text { tan una propuesta gráfica que combina la reproducción } \\
\text { precisa del filme original y, a la vez, la construcción de un } \\
\text { edificio propio, mediante un dibujo que remite a una base } \\
\text { fotográfica pero que se plasma sobre el papel un tanto } \\
\text { deslavazado (para bien), combinando lápiz y pintura, ade- } \\
\text { más de la elección de colores crema de corte melancólico. } \\
\text { Lo artificioso (no en un sentido peyorativo) de Wenders, } \\
\text { ese entramado intelectual expuesto a los cuatro vientos, } \\
\text { se refuerza a través de la concepción dramatúrgica de la } \\
\text { página, que se convierte en un escenario donde hacer pa- } \\
\text { sear en círculos a los personajes. } \\
\text { Última edición en español: Libros del Zorro Rojo, Barce- } \\
\text { lona, } 2016 \text {. }\end{array}$ \\
\hline $\begin{array}{l}\text { (La novela gráfica) Potemkin. } \\
\text { Homenaje a la película de Sergei } \\
\text { Eisenstein (2018) de Pablo Auladell } \\
\text { (autor completo). }\end{array}$ & $\begin{array}{l}\text { La aportación más notable del alicantino Pablo Auladell } \\
\text { reside, probablemente, en la voluntad de transportar in- } \\
\text { termedialmente el sentido del montaje rítmico de Eisens- } \\
\text { tein, que da cobertura a aquella idea del cine como una } \\
\text { bella mentira. }\end{array}$ \\
\hline $\begin{array}{l}\text { Basada en Bronenosets Potyomkin } \\
\text { (1925), dirigida por Sergei Eisenstein. } \\
\text { Conocida en España como El } \\
\text { acorazado Potemkin. }\end{array}$ & $\begin{array}{l}\text { Sin embargo, a pesar de que se trata de un cómic que ya } \\
\text { en el título se revela como homenaje, Auladell no renun- } \\
\text { cia a hacer acopio de recursos netamente historietísticos } \\
\text { como el contraste de la tonalidad grisácea salpicada de } \\
\text { rojos ocasionales y que evocan la revolución, el cambio, } \\
\text { la violencia. Asimismo, el trazo de solemnidad hierática } \\
\text { renacentista a lo Piero della Francesca, característico del } \\
\text { autor, no es dejado de lado sino fusionado, por más con- } \\
\text { tradictorio que parezca, con el dolor y la rabia de ese pue- } \\
\text { blo ruso que entraba en el siglo XXI anclado todavía en la } \\
\text { Edad Media. } \\
\text { Última edición en español: Libros del Zorro Rojo, Barce- } \\
\text { lona, } 2018 \text {. }\end{array}$ \\
\hline
\end{tabular}




\begin{tabular}{|l|l|}
\hline Obra seleccionada & Breve comentario sobre el motivo de selección \\
\hline $\begin{array}{l}\text { King Kong (2019) de Michel Piquemal } \\
\text { (guion) y Christophe Blain (dibujo). }\end{array}$ & $\begin{array}{l}\text { Entre los ítems seleccionados, tal vez sea el que vuela más } \\
\text { libre respecto a su referente original gracias a una medi- } \\
\text { tada intersección entre el álbum ilustrado y el cómic, en } \\
\text { lo que redunda la elección de una paleta de colores que } \\
\text { varía de más oscuridad a más claridad según se acerque a } \\
\text { por Merian C. Cooper y Ernest B. } \\
\text { Schoedsack. }\end{array}$ \\
$\begin{array}{l}\text { un medio u otro. Además, se debe destacar la opción por } \\
\text { condensar en unos pocos paneles la trama y confiar, así, } \\
\text { en abundantes ilustraciones a toda página que evocan la } \\
\text { sensación paisajística, lo exótico. } \\
\text { Por otra parte, el dibujo aparentemente suelto y liberado } \\
\text { de Blain conduce a un alto nivel de plasticidad, reminis- } \\
\text { cente del movimiento. En cuanto a la labor de Piquemal, } \\
\text { sus textos prosísticos ornamentan la página con un ritmo } \\
\text { narrativo similar al de las cartelas del cine mudo. } \\
\text { Última edición en español: Yermo Ediciones, Barcelona, } \\
2019 .\end{array}$ \\
\hline
\end{tabular}

Planteado ya el canon mínimo, el apartado siguiente se centrará en exponer un comentario concreto de una de las obras escogidas. Rogamos, al lector de este artículo, que lo tome como una muestra práctica de la aplicación (superficial, por primeriza) de los criterios de la tabla 1 para justificar académicamente la selección.

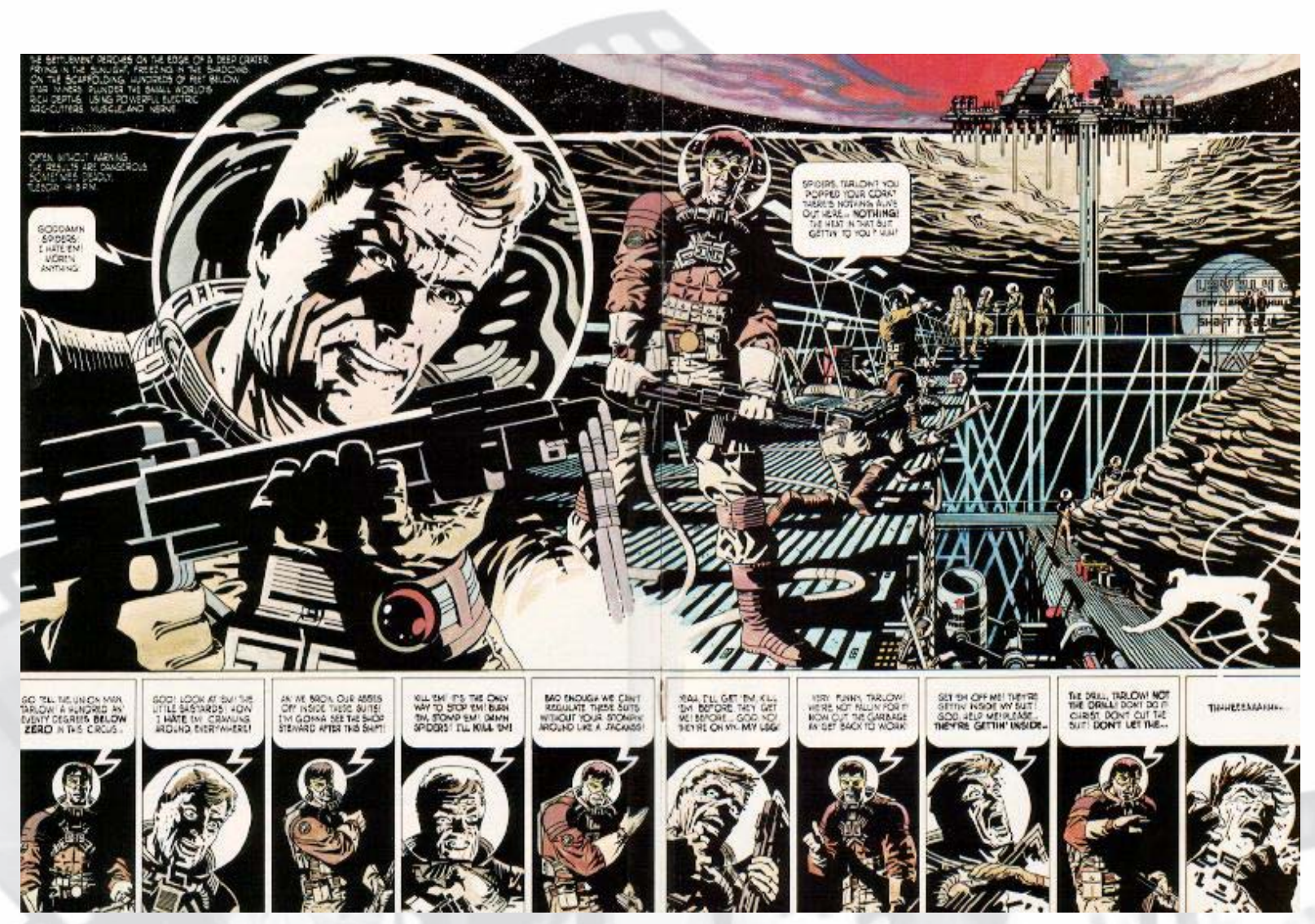

Una doble splash page en Outland (1981-1982) de Jim Steranko 


\section{LECCIÓN DE ANATOMÍA: ANÁLISIS ESPECÍFICO DE ALIEN: THE ILLUSTRATED STORY $(1979)^{17}$}

De todas las obras que hemos sugerido para conformar un canon de excelencia de adaptaciones de películas al cómic, hemos escogido Alien: The Illustrated Story (1979) por su valor, digamos, fundacional: hasta donde llega nuestro conocimiento, es la versión más antigua en que los historietistas muestran una voluntad que va más allá de lo funcional para desembocar en un artefacto disfrutable por sí mismo, si bien el diálogo con la fuente de la que nace redunda en el placer estético. Esta condición, por descontado, le otorga un carácter modélico (de estándar de calidad, por así decir) que, a nuestro juicio, justifica que la resaltemos especialmente, si bien se trata, si se nos permite el latinajo, de un caso de primus inter pares.

A estas alturas, poco se puede añadir para resaltar la transcendencia del filme dirigido por Ridley Scott en 1979 a partir de un guion de Dan O'Bannon. Obra maestra tanto de la ciencia ficción como del terror, debe su fama a diversos motivos pero, a juicio nuestro, fundamentalmente por dos aspectos: por un lado, el magnífico decorado, incluyendo la nave Nostromo, que se convierte en herramienta imprescindible para lograr el ambiente enrarecido (de tensión al borde del estallido) y que, en verdad, casi se configura como un personaje más de la trama, esto es, se concibe el locus donde circulan los personajes como actante; por otro, el diseño del monstruo al que alude el título, surgido de una pesadilla lovecraftiana abismal y ancestral, y que evoca, a un tiempo, a los demonios grotescos de los libros medievales miniados y al miedo al futuro incierto vía un organismo vivo que, sin embargo, se asemeja más en su configuración a la frialdad de las máquinas. Mediante ambas plasmaciones, aquella elaborada por los artistas conceptuales Ron Cobb y Chris Foss, y la segunda, resultado de la enfermiza creatividad de H. R. Giger, todo un referente iconográfico de los temores finiseculares de una humanidad que ha matado a Dios, la película accede a una dimensión casi nunca igualada, mucho menos superada (¿quizá The Thing (1982) de John Carpenter?), de paranoia e incertidumbre que se aloja, al acecho para destruir, en el interior del espectador como metáfora de la aberración alienígena misma.

Asimismo, cabe mencionar elogiosamente la decisión de mantener unos diálogos sucintos, más sugerentes que taxativos, a veces entrecortados (el anacoluto como instrumento comunicativo), entregados al doble sentido y que demandan al espectador grandes dotes de descodificación de las inferencias. En consonancia, el trabajo actoral remite a la contención dramática (se calla más que se dice, o mejor aún, se dice mucho mediante el silencio), a pesar de momentos puntuales que, precisamente, triunfan por contraste como la escena icónica de la muerte de Kane (interpretado por John Hurt) u, obviamente, el clímax final protagonizado por la teniente Ripley (Sigourney Weaver), por otra parte un personaje avanzado a su tiempo en función de su preconización de las heroínas fuertes que comienzan a ser moneda de cambio habitual en la ficción pop del siglo XXI. En esta misma línea de reposo interpretativo preñado de connotaciones semánticas, destaquemos también al capitán Dallas (Tom Skerritt), una suerte de héroe del western a la manera tranquila y de liderazgo compasivo y, al tiempo, convincente, de James Stewart.

17 Las referencias bibliográficas que proporcionan el fondo de datos sobre el cual reposar la reflexión personal son: por lo que respecta al cómic, Nolen-Weathington y Ash (2006), y Callahan (2012); en cuanto a la película, Mclntee (2005) y Barker, Egan, Ralph y Phillips (2016). 

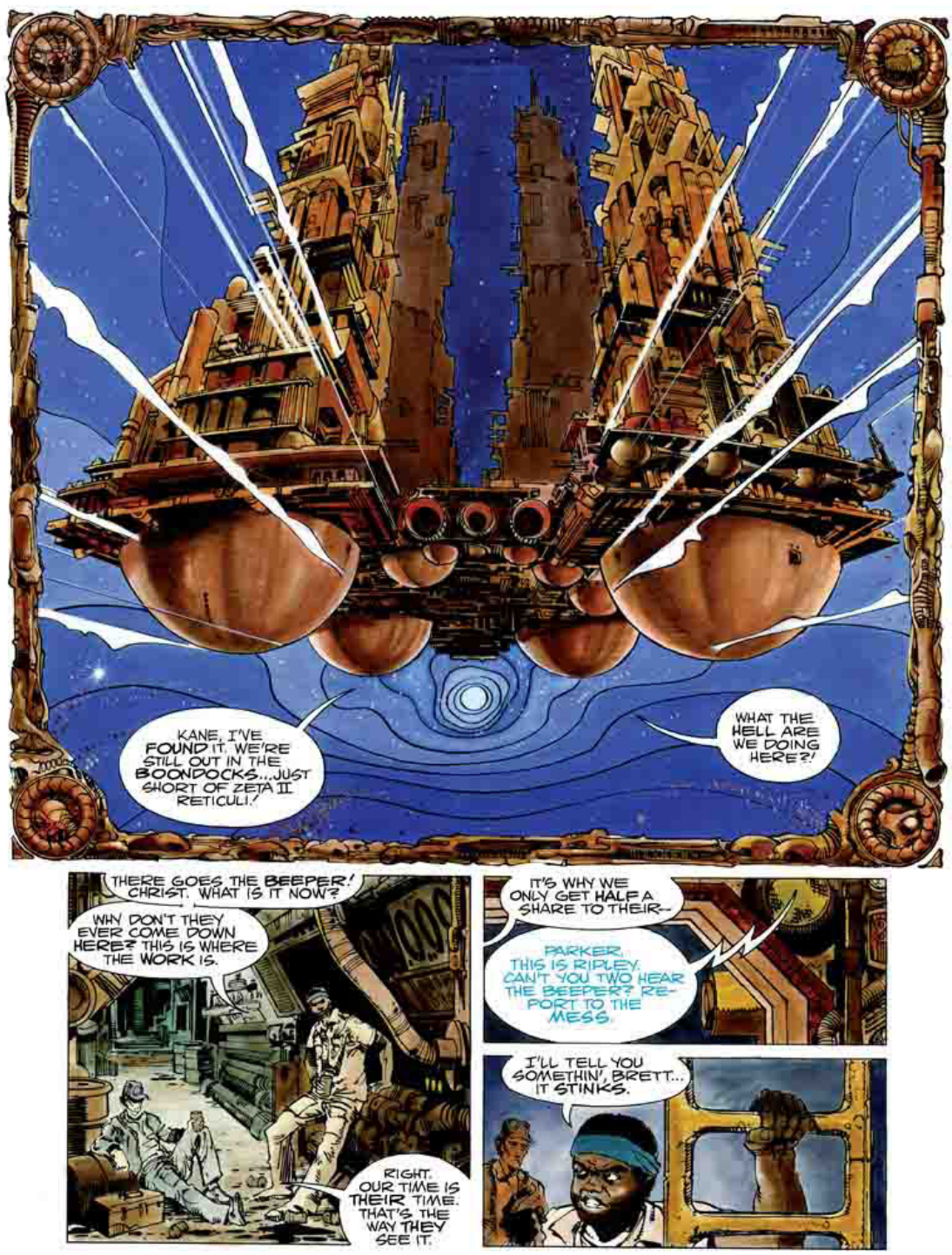

La Nostromo surcando el espacio como un sarcófago premonitorio del fatal desenlace

Además de los logros artísticos, Alien es también un referente comercial que, en puridad, ha dado lugar a una franquicia identificable con aquello que denominamos como universo expandido: secuelas al filme original, novelas, videojuegos, juguetes y, por descontado, cómics. No solo la adaptación aquí comentada, del mismo año 1979, sino toda una sucesión de cabeceras que, a pesar de que en algunos casos cuentan con aportaciones reseñables, dejaremos fuera de este subapartado por no dispersar el análisis. Así, la historieta concreta sobre la que ponemos el foco entre todas las adaptaciones escogidas es la de, ya lo hemos adelantado, Alien: The Illustrated Story con Archie Goodwin ${ }^{18}$ al

18 Guionista y editor ampliamente reconocido en la industria historietística de los EEUU, cabe destacar su trabajo como escritor principal, así como editor, de títulos de terror de la editorial Warren entre 1964 y 1967. Posteriomente, entre 1976 y 1977 fue editor-in-chief de Marvel Comics y, ya en la década de los ochenta, dirigió el magazine Epic Illustrated, editado bajo el sello Epics Comics, que también supervisó. Además de por sus guiones de terror y la propia adaptación de Alien, Goodwin es reconocido como autor por su trabajo para Star Wars (llevó la batuta inicial de la versión en comic book mensual para Marvel desde 1977) y su colaboración con Walter Simonson para el serial Manhunter (1973-1974) en la editorial DC Comics. 


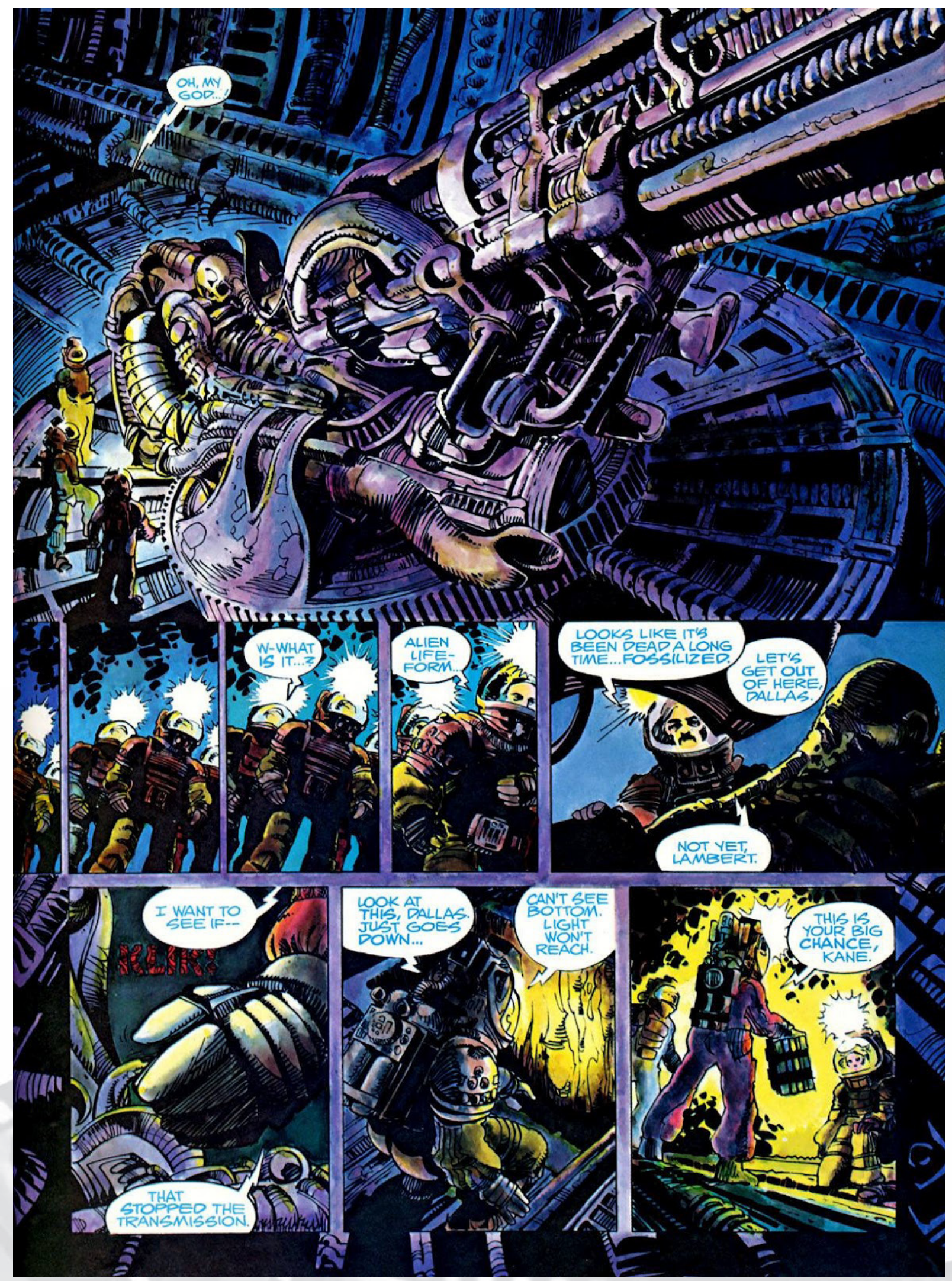

Ejemplo del diseño de página a manera de palimpsesto de viñetas 
guion y Walter Simonson ${ }^{19}$ en calidad de dibujante y responsable del grafismo en general. Esta adaptación, conformada por sesenta y cuatro páginas, fue publicada por primera vez por la revista Heavy Metal, si bien ha contado con sucesivas ediciones acompañadas de material extra (a la manera de las ediciones literarias críticas) que dan fe de su condición de clásico del medio.

En relación al ambiente opresivo del filme, se debe poner en valor el diseño de página de la adaptación. En este sentido, asistimos a menudo a una acumulación extraordinaria de viñetas que ralentizan el ritmo y contribuyen, así, a implementar una letargia ominosa; al mismo tiempo, frecuentemente ese haz de paneles se enmarca en splash pages (a veces, dobles), que sirven de tapiz y que aceleran el paso de la trama, lo que da como resultado una especie de palimpsesto que se desborda informativamente. Desde un punto de vista temporal en relación al proceso lector, este mecanismo permite que no sea necesario evocar la película fotograma a fotograma sino condensar la información de una manera diacrónica (las viñetas reflejan un punto en el tiempo; la splash page de fondo, otro), diferente de la temporalidad cinematográfica. Se pone en juego, pues, el potencial de expresar una simultaneidad de acciones que es inherente al uso extremo de la página de cómic como mapa del relato. Ante este alarde técnico, que no es tal pues no denota virtuosismo sino eficacia narrativa (sensorial, más que lineal), se siente la tentación de aplaudir estrictamente la planificación visual de Simonson, pero sin duda, atendiendo al trabajo previo de ambos como equipo en el serial Manhunter para DC Comics entre los números 437 y 443 de Detective Comics (1973-1974), Goodwin no es ajeno a la decisión y plantea un script historietístico que le encaja como un guante al dibujante.

En esta línea, deseamos fijarnos en la decisión de no añadir texto innecesario en cartelas (apenas hay un pequeño remedo de narrador omnisciente en píldoras extremadamente breves y marginales, algo más prominentes al principio para aclarar el dramatis personae y la ubicación general) y, en consecuencia, dejar vía libre a que fluya lo visual, con el apoyo, en todo caso, de unos diálogos aún más reducidos a la mínima expresión que en la película, si es posible ${ }^{20}$. Como consecuencia colateral notable, el silencio inherente al cómic como medio, por contraste con el cine, se resalta más por lo ajustado y preciso de las verbalizaciones. En una línea similar, Simonson, reconocido como uno de los mejores diseñadores de onomatopeyas en la historia del cómic americano (no solo por su valor plástico sino también por su uso como recurso narrativo, por ejemplo, para dirigir el ojo del lector), se muestra prudente y, por ello, destacan sobremanera las apariciones esporádicas en remisión, por ejemplo, a ruidos mecánicos de la nave. Por contraste, tal escasez se compensa, con suma sutileza, gracias al recurso algo más reiterado de las líneas cinéticas.

And last but not least, apuntemos el delicado equilibrio entre la referencia a los actores reales y la conservación del trazo propio del dibujante como signo fehaciente de la consecución de un grado de iconicidad lo suficientemente figurativo como para no alienar

19 Autor completo, a pesar de que se inició sobre todo como dibujante, la obra maestra de Walter Simonson remite, sin duda, a su etapa en la cabecera The Mighty Thor (primero, asumiendo tanto guion como dibujo, después en colaboración con Sal Buscema con este como responsable gráfico) para Marvel entre 1983 y 1987. Asimismo, en 1972 creó Star Slammers, que, bajo sucesivas iteraciones, se ha convertido en un clásico de la ciencia ficción crítica con el panorama paramilitar, reminiscente, tal vez del Starship Troopers de Robert A. Heinlein.

20 Mencionemos que la rotulación original se debe al mismo Simonson en colaboración con John Workman, otro referente del medio en los EEUU. 

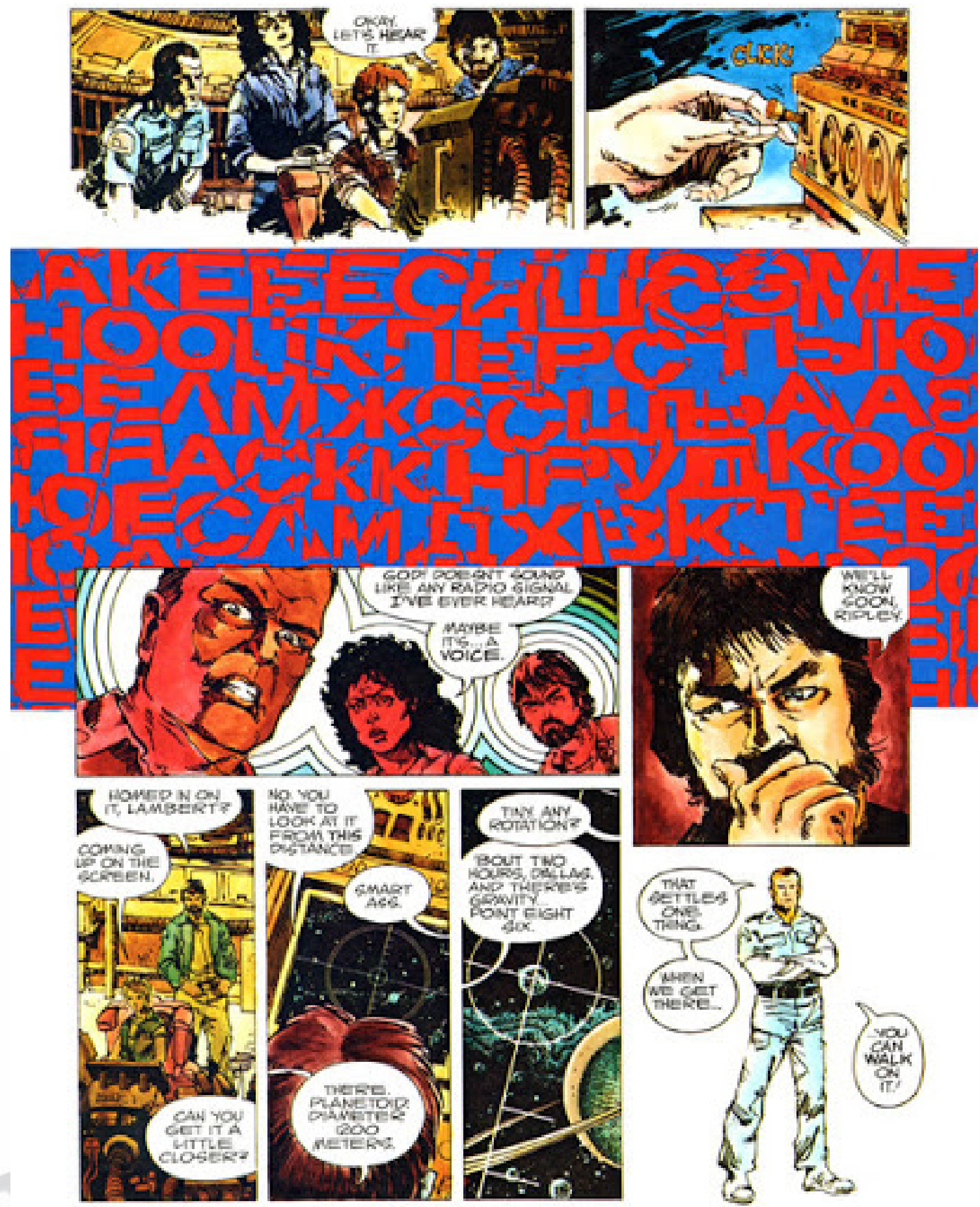

Uno de los escasos usos, pero brillantes, de las onomatopeyas en Alien: The Illustrated Story (1979)

al espectador ahora devenido lector, pero sin renunciar a la idiosincrasia del grafismo global. En esta misma senda cabría incluir un uso expresivo del color ${ }^{21}$, que, en líneas generales, tiende a una cierta aridez vinculable con la pauta sombría de lo que se narra pero que, eventualmente, recurre a estallidos de colores para romper la monotonía y mantener alerta al leyente.

21 Responsabilidad colectiva de Polly Law, Bob K. LeRose, Deb Pedlar, Louise Simonson y el propio Walter Simonson, que actúa como supervisor final. 


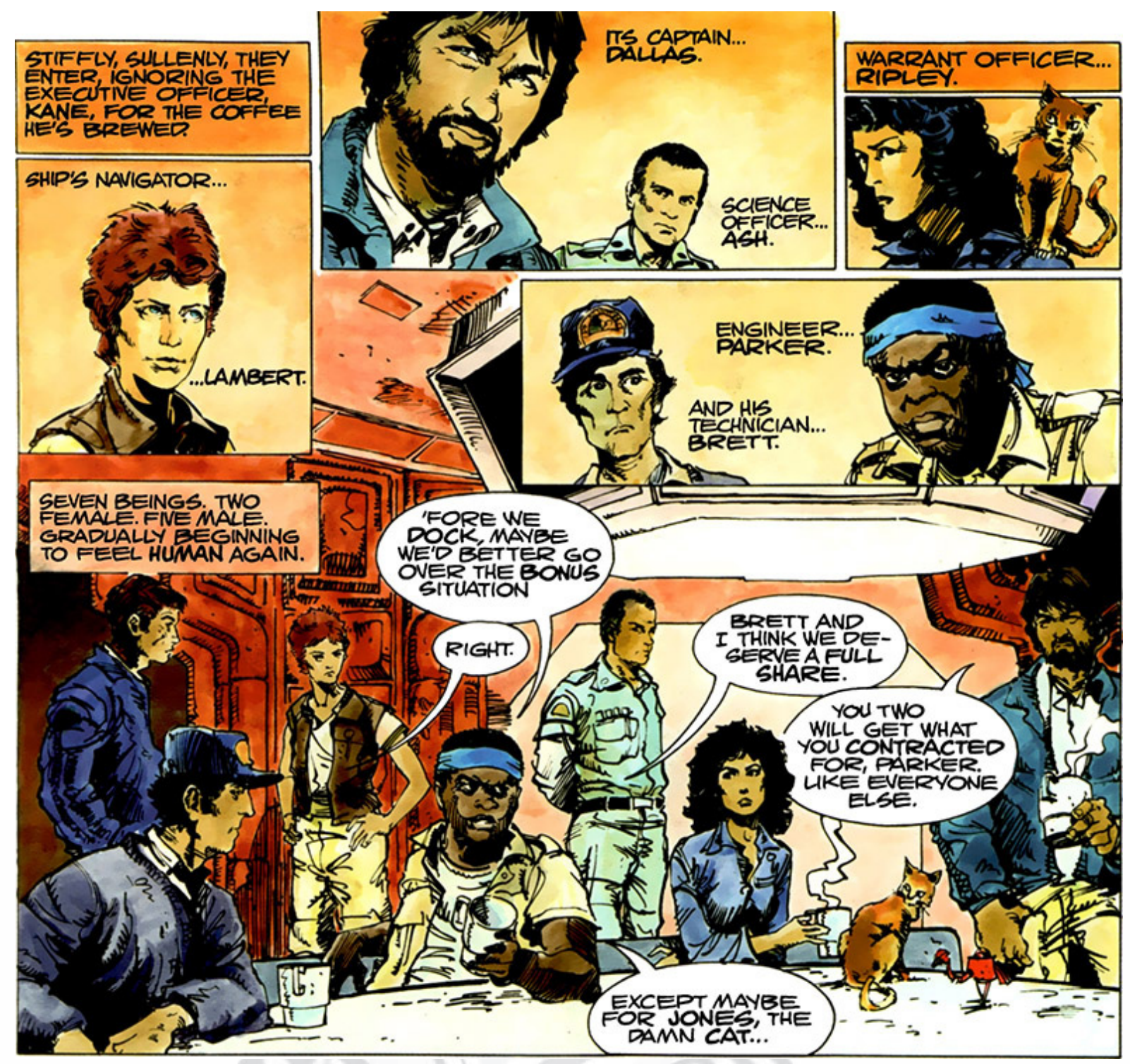

Actores reconocibles pero sin traicionar el trazo característico de Walter Simonson

\section{TO BE CONTINUED: CONCLUSIONES PROVISIONALES}

Al contrario de cierta cantinela que tiende a describir los tiempos recientes como marco de degradación de la sensibilidad artística, defendemos que lo que verdaderamente caracteriza a la contemporaneidad es la democratización de la experiencia cultural (Lipovetsky y Serroy, 2016: 280). Esto es: se publica más que nunca y, además, el consumidor cuenta con una facilidad de acceso extremadamente mayor que en el pasado, por lo que en justicia lo que corresponde al crítico es leer con detenimiento y analizar concienzudamente para rescatar el oro del barro, en lugar de dejarse embargar por lamentos plañideros influidos por el manido discurso de la (supuesta) alta cultura. Así, en un contexto, cierto es, tan sometido a los vaivenes caprichosos de la mercadotecnia como es el de la cultura industrial, al que pertenecen tanto el cómic como el cine, cabe atender con perspicacia a aquellas obras que sobresalgan de lo anodino y que, por tanto, ofrezcan valores superadores de lo meramente circunstancial para, así, constituirse en referentes perdurables. 
En el contexto específico de las adaptaciones del cine al cómic, que ha sido objeto del presente trabajo, sin duda abundan los ejemplos que apenas presentan más interés que no sea el de soporte comercial del filme original (algo, por otra parte, perfectamente lícito y cuyo estudio, como ejercicio académico, podría ser tremendamente sugestivo), pero una mirada pausada a la producción de las últimas décadas y, especialmente, del último decenio, nos pone sobre la pista de ítems valiosos. En este sentido, ha sido el propósito de nuestro artículo colocar, mediante una selección breve, una primera piedra de un edificio en torno al concepto del canon artístico y que resta pendiente de depuración y, si cabe, de finalización pasando del personalismo al consenso entre expertos. No obstante, no nos quedemos en la anécdota de los artefactos escogidos ${ }^{22}$ y, por el contrario, aboguemos por estimar como metodología altamente productiva aquella que, partiendo del paradigma intermedial, pone el foco sobre el carácter interdisciplinario del cómic y, en consecuencia, en su enigmático proceso de lectura, en el que el lector adquiere un rol tal vez más significativo que en otros medios.

Por otra parte, valga este trabajo como acicate para investigaciones futuras que no solo amplíen la selección sino que la justifiquen a partir de reflexiones concretas sobre cada obra $y$, así, iniciar un camino de perfección que conduzca a un concepto multimodal de la lectura, sin duda uno de los grandes retos del presente cultural.

\section{BIBLIOGRAFÍA CITADA}

AHMED, M., Openness of Comics: Generating Meaning within Flexible Structures, Jackson, University Press of Mississipi, 2016.

AltARRIBA, A., «La historieta, un medio mutante», Quimera, 293 (2008); <http://www.antonioaltarriba.com/wp-content/uploads/2012/04/H00EC06.pdf> [consulta: 13 abril 2020].

BARKER, M., EgAN, K., RALPH, S. y PHILLIPS, T., Alien Audiences: Remembering and Evaluating a Classic Movie, Londres, Palgrave Macmillan, 2016.

BARTHES, R., Le plaisir du texte, París, Éditions du Seuil, 1973.

-, La cámara lúcida. Nota sobre la fotografía, Barcelona, Paidós Ibérica, 1990.

BERONE, L., «La literatura en pedazos: el problema de la adaptación», Tebeosfera, 1(2) (2008); <http://www.tebeosfera.com/documentos/textos/la literatura en pedazos.html> [consulta: 27 marzo 2020].

BORDES, E., Cómic, arquitectura narrativa, Madrid, Cátedra, 2017.

Callahan, T., «Revisiting Goodwin \& Simonson's Alien», Comic Book Resources, (2012); $<$ https://www.cbr.com/revisiting-goodwin-simonsons-alien/> [consulta: 13 marzo 2020].

CASETtI, F., Communicative Negotiation in Cinema and Television, Milán, Vita e Pensiero, 2002.

Dixon, W. W. y Graham, R., A Brief History of Comic Book Movies, Londres, Palgrave Macmillan, 2017.

GARCíA, S., La novela gráfica, Bilbao, Astiberri, 2010.

GeneTTE, G., Palimpsestos. La literatura en segundo grado, Madrid, Taurus, 1989.

GIMFERRER, P., Cine y literatura, Barcelona, Seix Barral, 2005.

22 Por bien que la pasión por las listas, Umberto Eco mediante, remite a un placer culpable que potencia la reflexión y desafía al conformismo puesto que nos obliga a elegir y, por tanto, a descartar. 
Greimas, A. J. y Courtes, J., Semiótica. Diccionario razonado de la teoría del lenguaje, Madrid, Gredos, 1982.

Groensteen, T., Système de la Bande Dessinée, París, Presses Universitaires de France, 1999. -, Un objet culturel non identifié: la bande dessinée, Angulema, Éditions de l'an 2, 2006.

HATFIELD, C., "An Art of Tensions», Alternative Comics: An Emerging Literature, Jackson, University Press of Mississipi, 2005, pp. 32-67.

HILL, J. y GiBSON, P. C., The Oxford Guide to Film Studies, Nueva York, Oxford University Press, 1998.

JENKINS, H., «Transmedia Storytelling. Moving Characters from Books to Films to Video Games can Make them Stronger and more Compelling", (2003); $<$ http://www.technologyreview.com/news/401760/transmedia-storytelling > [consulta: 12 abril 2020].

JIMÉNEZ VAREA, J., Narrativa gráfica: narratología de la historieta, Madrid, Fragua, 2016.

KRESS, G. R. y VAN LEEUWEN, T., Multimodal Discourse. The Modes and Media of Contemporary Communication, Londres, Arnold, 2001.

KRISTEVA, J., Semiótica, 2 volúmenes, Madrid, Fundamentos, 1978.

LIPOVETSKY, G. y SERROY, J., La estetización del mundo. Vivir en la época del capitalismo artístico, Barcelona, Anagrama, 2016.

MATLY, M., «Hacia un análisis funcional del cómic», LIJ Ibero, 6 (2018), pp. 37-51.

MCINTEE, D., Beautiful Monsters: The Unofficial and Unauthorized Guide to the Alien and Predator Films, Surrey, Telos Publishing, 2005.

MURO MuniLla, M. Á., Análisis e interpretación del cómic: ensayo de metodología semiótica, Logroño, Universidad de La Rioja, 2004.

Nolen-Weathington, E. y Ash, R., Modern Masters Volume 8: Walter Simonson, Raleigh, TwoMorrow's Publishing, 2006.

ROVIRA-COLLADO, J., "Canon artístico y criterios de selección de historietas: las propuestas de Unicómic», Umbral. Literatura para infancia, adolescencia y juventud, 12(3) (2017), pp. 3-19.

SANDERS, J., Appropriation and Adaptation, Nueva York, Routledge, 2005.

SCOLARI, C. A., Narrativas Transmedia. Cuando todos los medios cuentan, Barcelona, Deusto, 2013.

SOUSANIS, N., Unflattening, Cambridge / Londres, Harvard University Press, 2015.

VARILLAS, R., La arquitectura de las viñetas. Texto y discurso en el cómic, Sevilla, Viaje a Bizancio Ediciones, 2009.

YEXUS, «Literatura en viñetas», CLIJ, 85 (1996), pp. 60-63.

YUS RAMOS, F., La interpretación y la imagen de masas, Alicante, Institut de Cultura «Juan Gil-Albert» / Generalitat Valenciana. Conselleria de Cultura, Educació i Ciència, 1997.

ZUNZUnegul, S., Pensar la imagen, Madrid, Cátedra / Universidad del País Vasco, 2010. 